\title{
Broadband Solar Absorber Based on Square Ring cross Arrays of $\mathrm{ZnS}$
}

\author{
Feng $\mathrm{Xu}{ }^{1}$, Lixia Lin ${ }^{1}$, Jun Fang ${ }^{1}$, Mianli Huang ${ }^{1}$, Feng Wang ${ }^{2}$, Jianzhi Su ${ }^{2}$, Shufen $\mathrm{Li}^{2}$ and Miao Pan ${ }^{2, *}$ \\ 1 College of Chemical Engineering and Materials Science, Quanzhou Normal University, \\ Quanzhou 362000, China; Fengxu202101@163.com (F.X.); 13774559778@163.com (L.L.); \\ fangjun@qztc.edu.cn (J.F.); mianlihuang@qztc.edu.cn (M.H.) \\ 2 College of Physics \& Information Engineering, Quanzhou Normal University, Quanzhou 362000, China; \\ fwang99@126.com (F.W.); sujianzhi@126.com (J.S.); shufenli55@163.com (S.L.) \\ * Correspondence: miaopan2021@163.com; Tel./Fax: +86-057-2232-1297
}

check for updates

Citation: Xu, F.; Lin, L.; Fang, J.; Huang, M.; Wang, F.; Su, J.; Li, S.; Pan, M. Broadband Solar Absorber Based on Square Ring cross Arrays of $\mathrm{ZnS}$. Micromachines 2021, 12, 909. https:// doi.org/10.3390/mi12080909

Academic Editor: Francesco Di Giacomo

Received: 2 June 2021

Accepted: 23 July 2021

Published: 30 July 2021

Publisher's Note: MDPI stays neutral with regard to jurisdictional claims in published maps and institutional affiliations.

Copyright: (c) 2021 by the authors. Licensee MDPI, Basel, Switzerland. This article is an open access article distributed under the terms and conditions of the Creative Commons Attribution (CC BY) license (https:/ / creativecommons.org/licenses/by/ $4.0 /)$.

\begin{abstract}
Solar energy is an inexhaustible clean energy. However, how to improve the absorption efficiency in the visible band is a long-term problem for researchers. Therefore, an electromagnetic wave absorber with an ultra-long absorption spectrum has been widely considered by researchers of optoelectronic materials. A kind of absorbing material based on ZnS material is presented in this paper. Our purpose is for the absorber to achieve a good and wide spectrum of visible light absorption performance. In the wide spectrum band $(553.0 \mathrm{THz}-793.0 \mathrm{THz})$ of the absorption spectrum, the average absorption rate of the absorber is above $94 \%$. Using surface plasmon resonance (SPR) and gap surface plasmon mode, the metamaterial absorber was studied in visible light. In particular, the absorber is insensitive to both electric and magnetic absorption. The absorber can operate in complex electromagnetic environments and at high temperatures. This is because the absorber is made of refractory metals. Finally, we discuss and analyze the influence of the parameters regulating the absorber on the absorber absorption efficiency. We have tried to explain why the absorber can produce wideband absorption.
\end{abstract}

Keywords: solar absorber; broadband; perfect absorption; surface plasmon

\section{Introduction}

One of the major issues that are limiting the development of human society is the energy crisis. The most promising new green energy source for the twenty-first century is solar energy. One way to effectively alleviate the energy crisis is to make full use of solar energy. We know that broadband absorption close to the solar spectrum is necessary to effectively collect and use solar energy. Plasmon absorbers with unique subwavelength trapping capability have received special attention from researchers [1-4]. In 2008, Landy et al. proposed an electromagnetic wave absorber, which attracted the attention of researchers [5]. We observe visible light on Earth at frequencies ranging from $380 \mathrm{THz}$ to $850 \mathrm{THz}$. The best way of obtaining solar energy is through solar thermal systems [6]. A perfectly designed absorber is the key to a solar thermal system being able to absorb solar radiation perfectly. An ideal absorber should have a sufficiently broad absorption curve with good absorption performance in the visible wavelength band. The absorber should also be insensitive to electric field absorption and magnetic field absorption [7-10]. We combine multiple surface pattern structures in the absorption layer of the same resonant cell to achieve broadband absorption [11-14]. This multi-resonance combination method can make multiple resonance absorption peaks in the spectrum overlap with each other. We end up with a wide absorption bandwidth $[15,16]$. However, the broadband of the absorber cannot be infinitely wide due to the influence of adjacent resonant arrays and the fact that an array of cells can only accommodate a limited combination of resonator stacks [17]. Au can produce plasmon resonance and optical coupling. Therefore, Au is used in the metal material of the absorber designed in this paper [18]. 
Metamaterials have unique absorption properties. Using metamaterials to design ideal absorbing materials has become the focus of researchers [19-22]. Metamaterials can completely absorb microwaves. Metal-insulator-metal (MIM) consists of three parts of a plasmon absorber. The stack structure of the absorber can accomplish multi-band spectral absorption or wide spectrum absorption [23-28]. The top layer of the metal-insulatormetal absorber is composed of a metal array pattern, the middle layer is a dielectric layer, and the bottom is a metal substrate to prevent transmission. The bottom metal film is used to prevent the transmission of electromagnetic waves. The patterned metal structure on the top layer is used to match the spatial impedance and suppress the reflection of electromagnetic waves. In addition, the ability of metamaterial absorbers to absorb light depends not only on the material itself but also on its shape, size, arrangement, and structure. Many researchers have designed solar absorbers based on membrane stacking, but these absorbers usually have very narrow absorption bands [29-31]. In 2017, Luo et al. developed a sandwich structure metamaterial based on nickel (Ni) film [32]. In this metamaterial structure, SPP resonance is excited at the interface of Ni film and air. A resonant cavity mode exists in the grooves of the absorber. The integration of the SPP syntony and the resonator mode results in a wide band response. Ni has a strong absorption property in the visible band. Therefore, the sandwich metamaterial structure has perfect absorption performance in the whole visible light band. In 2017, Cao et al. realized the perfect absorption of the whole visible band by using Ge2Sb2Te5 material with a large imaginary part of dielectric function in the visible band [33]. Takatori et al. developed a silver-based broadband absorber. The average absorption rate of the silver-based absorber is more than $50 \%$ in the wavelength range of $400 \mathrm{~nm}-3200 \mathrm{~nm}$ [34]. The combination of surface plasmon resonance and resonant cavity mode can localize the electromagnetic field in the dielectric gap to achieve near-perfect absorption [35-38].

Inspired by the literature published by Luo in 2017, we decided to adopt the stack structure of a thin film layer to achieve better absorption efficiency in the visible light band. Inspired by Cao et al.'s literature in 2017, we used refractory precious metal gold to replace silver material so that the absorber can still maintain a high absorption rate at high temperatures. The former work uses the combination of surface plasmon resonance (SPR) and cavity mode to enhance absorption. Therefore, this paper also designed the structure to make the surface plasmon resonance and resonant cavity mode obtain better absorption efficiency. ZnS material is an important II-VI compound semiconductor. ZnS material is a kind of common wide bandgap semiconductor material. $\mathrm{ZnS}$ nanomaterials have attracted much attention. In this paper, a broadband absorber with a multilayer structure based on $\mathrm{ZnS}$ material is proposed. The structure of the absorber and the materials used can interact to produce surface plasmon resonance. Surface plasmon resonance results in strong absorption or scattering of incident photons on the metal surface. The absorber concentrates the energy of the electromagnetic field in the subwavelength range, so the absorber produces a very strong light field enhancement effect. This effect greatly increases the interaction between light waves and absorbent materials. Therefore, we could obtain an absorber with good performance and a wide spectrum. Notably, the multilayer metamaterial achieved an average good absorption rate of $94 \%$ across the $240 \mathrm{THz}$ spectrum, with a single peak of up to $99.7 \%$ at $396.0 \mathrm{THz}$. In addition, the absorptivity is insensitive to polarized light. The absorber based on precious metal will deform at a relatively low temperature. Strong plasmon resonance can enhance the absorption of light. When the structure is exposed to strong light, the structure of the absorber based on precious metal may deform and lose its original absorption performance. The UWB absorber we proposed is based on refractory metal and semiconductors, which can maintain a stable structure at high temperatures [39]. Therefore, our proposed ultra-wideband electromagnetic wave absorber has wide application foreground in the fields of thermal photovoltaic, transducer, cloaking, and infrared detection [40-44]. At the same time, this paper can provide some suggestions for the design of the absorber of the film stack structure. 


\section{Design and Structure}

Figure 1 shows the structure of the absorber. Each cell array consists of three layers stacked on top of each other [45-47]. The top layer is composed of an Au microstructure layer. The dielectric function of Au film is the Drude model [48]. The structural parameters of the metamaterial are shown in Figure 1. The period width of the absorber is $\mathrm{W} 1=1000 \mathrm{~nm}$, and the width of the square ring structure is $\mathrm{W} 2=800 \mathrm{~nm}$, the square ring spacing is W3 $=100 \mathrm{~nm}$, the cross-structure width is $\mathrm{W} 4=140 \mathrm{~nm}$, and the thickness of the absorption layer is $\mathrm{h} 3=80 \mathrm{~nm}$. A semiconductor material $\mathrm{ZnS}$ is used as the dielectric layer in the middle, and its thickness is $\mathrm{h} 2=40 \mathrm{~nm}$. We use the Au layer with $\mathrm{h} 1=200 \mathrm{~nm}$ thickness at the bottom to eliminate the transmission in order to make the absorber transmittance zero. The total thickness of the whole nanocavity is $320 \mathrm{~nm}$. COMSOL software was used to verify whether the absorber proposed has a good absorption effect [49]. In this paper, the absorption characteristics of square cross multilayer metamaterials are simulated by using the finite element method. The boundary conditions during simulation are set as follows. The top layer of the air layer outside the absorber is modeled with the perfect matching layer and the scattering boundary conditions. The goal is to allow as much plane light with frequencies between $380 \mathrm{THz}$ and $850 \mathrm{THz}$ to shine vertically into the absorber from above the $z$-axis. Since the absorber is composed of multiple repeated cell arrays, we set Floquet periodic boundary conditions around the cell arrays. The research of an array of cells in the absorber can reduce the computational burden.

(a)

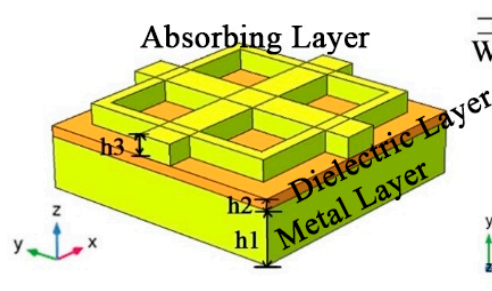

(b)

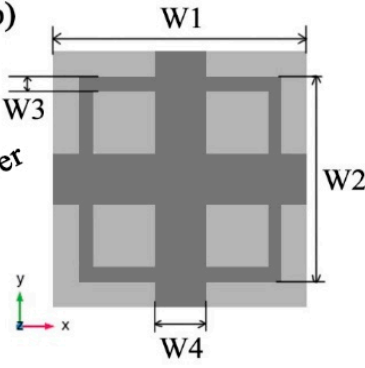

(c)

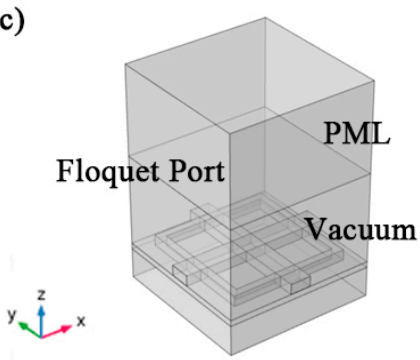

Figure 1. Schematic diagram of the base absorber: (a) schematic diagram of the three-dimensional structure of the ultra-broadband solar absorber. (b) Top view of the absorber structure. (c) the perfect matching layer (PML) of the base absorber.

\section{Results and Discussion}

As the thickness of $\mathrm{Au}$ is much larger than that of the substrate through which the electromagnetic wave can penetrate, the transmittance of the structure is basically zero. The absorption spectrum of multilayer stacked metamaterials can be calculated by $A=1-R$ [50-54]. As shown in Figure 2a, the absorption spectrum is marked by red lines, and the reflectivity is represented by black lines. As can be seen from Figure 2a, there is one peak in the low-frequency part and two peaks in the high-frequency broadspectrum absorption part. The three different peaks are $396 \mathrm{THz}, 582 \mathrm{THz}$, and $738 \mathrm{THz}$, and their respective absorptions are $99.67 \%, 98.71 \%$, and $99.61 \%$, respectively. Therefore, the structure we researched has wider and better absorption lines. As shown in Figure 2b, we compare the absorption spectra with and without the top antireflection layer. When there is an antireflective layer on the top, the absorber has better absorption performance. The absorbency of the absorber is more than $90 \%$ in the wavelength range of $240 \mathrm{THz}$, with an average absorbency of $94 \%$. There are two maximum absorption peaks, $\mathrm{f} 2$ and $\mathrm{f} 3$, in the broad spectrum, and the absorptions are $98.71 \%$ and $99.61 \%$, respectively. There is a single peak $\mathrm{f} 1$ with perfect absorption in the low-frequency part, and the maximum absorption is $99.7 \%$. When there is no absorption layer, we can see from Figure $2 b$ that the absorption efficiency of the absorber to visible light is very low. The results show that the uppermost structure contributes the most to light absorption. 
(a)

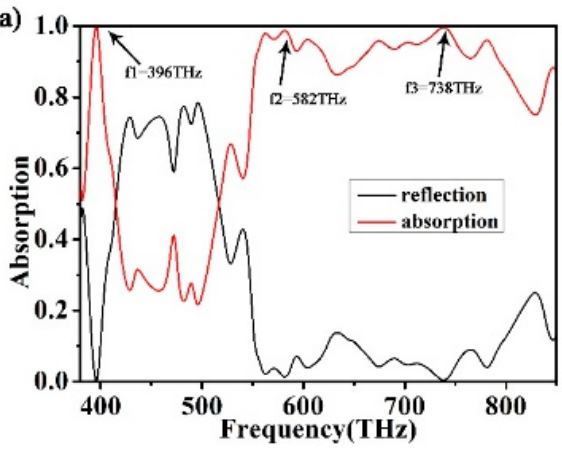

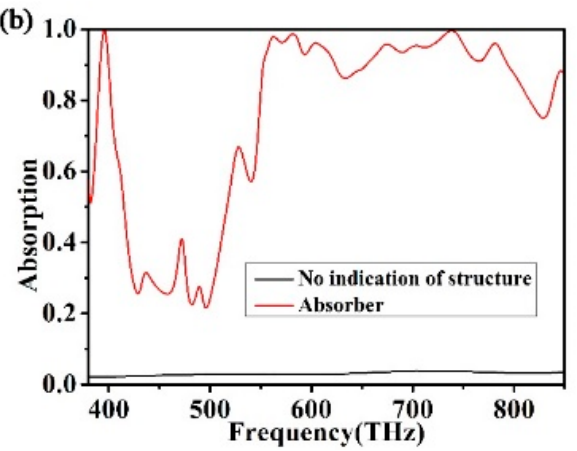

Figure 2. (a) Ultra-broadband spectrum of a solar absorber. (b) Spectrum of an absorber without surface structure.

To evaluate the performance excellence of the proposed structure, we compare the results with other similar absorbers, as shown in Table 1. Obviously, our proposed absorber has a higher average absorption rate in the visible band

Table 1. Comparison with other similar visible band absorbers.

\begin{tabular}{cccc}
\hline Refer. & Absorption Band-Width & Modulation Depth & $\begin{array}{c}\text { The Average } \\
\text { Absorption }\end{array}$ \\
\hline This article & $553 \mathrm{THz}-793 \mathrm{THz}$ & Over $90 \%$ & $94 \%$ \\
{$[55]$} & $523-592.5 \mathrm{THz}$ & Over $90 \%$ & $<90 \%$ \\
{$[56]$} & $375 \mathrm{THz}-750 \mathrm{THz}$ & Over $90 \%$ & $70 \%$ \\
{$[57]$} & $481.2 \mathrm{THz}-684.0 \mathrm{THz}$ & Over $90 \%$ & $92 \%$ \\
{$[58]$} & $430 \mathrm{THz}-770 \mathrm{THz}$ & Over $90 \%$ & $93.7 \%$ \\
{$[59]$} & $400 \mathrm{THz}-750 \mathrm{THz}(\mathrm{N}=2)$ & Over $90 \%$ & $90 \%$ \\
\hline
\end{tabular}

We simulated the electric field distribution at absorption peaks $\mathrm{f} 1, \mathrm{f} 2$, and $\mathrm{f} 3$, in order to understand why the absorber can absorb solar radiation in the visible band. We know that the SPP response can be excited at the metal-dielectric interface by the incident electromagnetic wave. The MIM structure has two metal-dielectric interfaces, and the two SPP modes are coupled in the dielectric layer to form the interstitial surface plasmon mode. The gap surface plasmon mode is derived from the coupling of two SPP modes. Therefore, the gap surface plasmon modes propagate along the polarization direction. The propagation of this mode is limited at the $z$ axis. A schematic diagram of electric field in X-Y plane is shown in Figure 3a-c. The frequency of absorption peak f1 is $396 \mathrm{THz}$. The gap surface plasmon modes propagate along the $y$-axis direction. When the surface structure size meets certain conditions, the gap surface plasmon modes propagate along the y-axis in both forward and backward directions. The absorber will produce a perfect absorption peak due to the standing wave syntony of a specific wavelength. The frequency of the absorption peak $\mathrm{f} 2$ is $582 \mathrm{THz}$, and the absorption excited by the electric field is distributed in the $y$-axis direction of the pattern layer on the top of the absorber. The distribution of the electric field enhances the absorption between the absorbing layer and the dielectric layer. Absorption peak $\mathrm{f} 3$ is located at $738 \mathrm{THz}$. The electric field distribution is similar to that of $\mathrm{f} 2$. As can be seen from Figure 4a, each cell array in the absorption layer excites surface plasmon between the top Au layer and the $\mathrm{ZnS}$ layer. The results show that the incident electromagnetic wave excites the SPP and forms the gap surface iso-polariton mode on the absorber, which enhances the light absorption. These electric fields are tightly confined between the metal and the medium. From Figure $4 b, c$, we can conclude that the absorption enhancement excited by the electric field is concentrated in the $y$-axis direction of the absorption layer. In the $x$ direction, the incident electric field of the absorber is mainly confined to the dielectric layer. In summary, the square ring cross absorber designed in this paper can achieve broad-spectrum light absorption mainly by 
excitation of the surface plasmon and interstitial surface plasmon mode. The absorber relies on standing wave resonance to achieve a strong electric field localization effect to achieve the perfect absorption peak at $\mathrm{f} 1$.

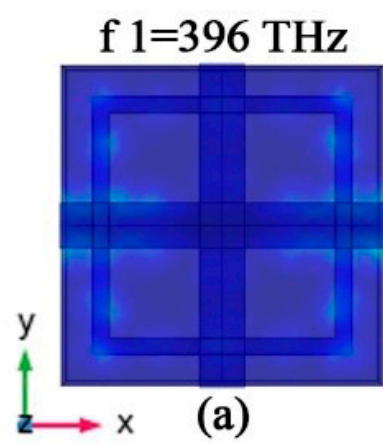

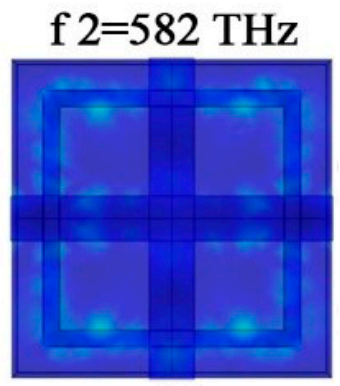

(b)

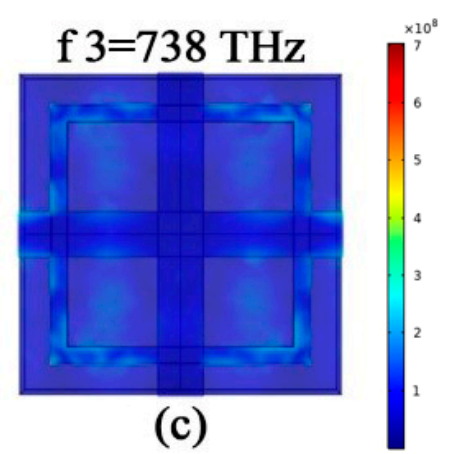

(c)

Figure 3. (a) Electric field diagram for a frequency of $396 \mathrm{THz}$. (b) Electric field diagram for a frequency of $582 \mathrm{THz}$. (c) Electric field diagram for a frequency of $738 \mathrm{THz}$.

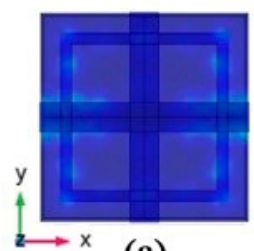

(a)

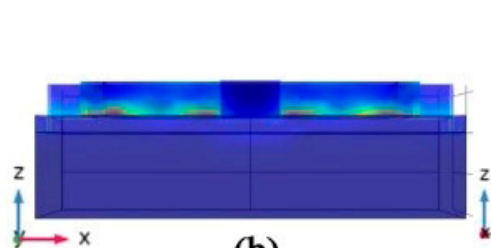

(b)

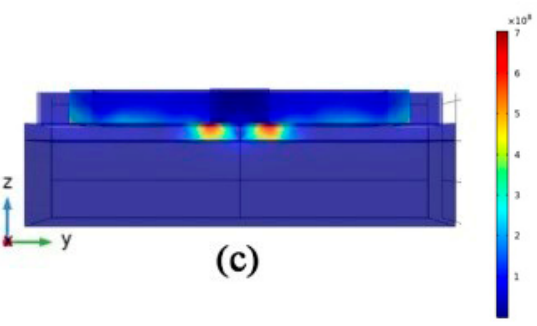

Figure 4. (a) top view of the electric field at a frequency of $396 \mathrm{THz}$. (b) Electric field view from the $y$-axis direction; (c) electric field view from the $x$-axis direction.

The aim of this study is to investigate whether changing the structural parameters affects the performance of the absorber. An attempt was made to adjust the structural parameters of the metamaterial absorber. We adjusted the spacing of the top square ring structure W3. The absorption effect is shown in Figure 5a. We changed the distance W3 of the square ring structure of the absorber from $80 \mathrm{~nm}$ to $120 \mathrm{~nm}$ in steps of $10 \mathrm{~nm}$. The absorption peak of the absorber increased from $83.3 \%$ to $99.59 \%$ at $\mathrm{f1}$ and from $92.0 \%$ to $99.1 \%$ at $\mathrm{f} 2$. The absorption performance of the absorber is significantly improved. While the absorption peak of $\mathrm{f} 3$ fluctuated slightly, the absorption of the absorber at the frequency of $\mathrm{f} 3$ first dropped from $99.4 \%$ to $98.2 \%$ and then rose to $99.4 \%$. The absorption band of the absorber gradually widened, and the absorption rate between $\mathrm{f} 1$ and $\mathrm{f} 2$ also increased to more than $87.5 \%$. The reason for these phenomena is that $\mathrm{ZnS}$ nanometer resonators provide effective resonance absorption through square ring resonance and cross plasmon resonance [60,61]. Therefore, in order to obtain an ideal absorption peak, appropriate square ring resonance and cross resonance should be adjusted to maximize the superposition resonance absorption. The superposition of absorption peaks produces ultra-wideband absorption. At $\mathrm{f} 1$ and $\mathrm{f} 2$, the resonance of the absorber is significantly enhanced with the decrease of W3. The resonance reaches the maximum at W3 $=100 \mathrm{~nm}$. We can observe and conclude from Figure $5 b$ that as W4 increases, the absorption peak of the absorber at $\mathrm{f} 2$ also increases. The absorptivity of the absorber increased from $97.34 \%$ to $99.85 \%$. When $\mathrm{W} 4=160 \mathrm{~nm}$, the resonance absorption of the absorber reaches the maximum, and the absorption efficiency graph is red-shifted. The resonance of the absorber reaches the maximum at $\mathrm{W} 4=150 \mathrm{~nm}$, and the absorption peak at $\mathrm{f} 3$ reaches $99.85 \%$. When $\mathrm{W} 4=150 \mathrm{~nm}$, the absorbance of $\mathrm{f} 3$ is as high as $99.9 \%$, but the absorption efficiency of the absorber is not as wide as that of $W 4=140 \mathrm{~nm}$. In addition, we can also observe that the structural parameters change in a wide range, and the absorber can still 
maintain a wide absorption bandwidth and high absorption efficiency. These characteristics will be beneficial to physical manufacturing because the absorber has a high tolerance.

(a)

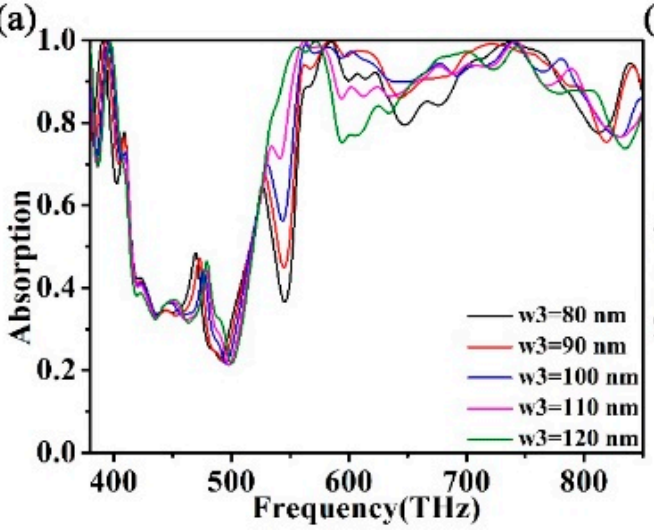

(b)

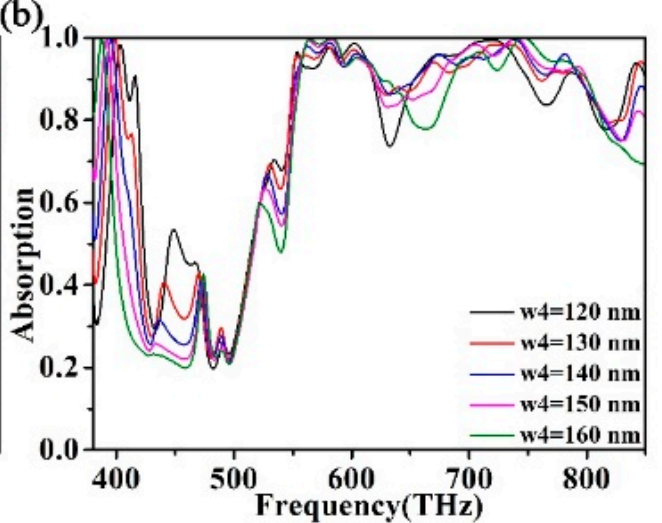

Figure 5. (a) The effect of square ring spacing W3 on the absorption spectrum. (b) The effect of cross-width W4 on the absorption spectrum.

Afterward, we wanted to find out whether changes in the thickness of the film would have an effect on the absorption spectrum. We changed the $\mathrm{ZnS}$ film thickness h2 and Au film thickness h3 of the absorber. Observing Figure 6a, it can be concluded that as the $\mathrm{ZnS}$ film thickness h2 increases, the absorber appears red-shifted, and the overall absorption efficiency moves towards the lower frequencies. The absorption peak of the absorber at f1 fluctuates greatly. The absorption efficiency of the absorber increased from $24.0 \%$ to $99.68 \%$ and then decreased to $55.94 \%$ due to the red-shifted of the absorption peak at $\mathrm{f} 1$. The absorption peaks of the absorber begin to split at $\mathrm{f} 2$ and $\mathrm{f} 3$. The absorption efficiency between $\mathrm{f} 2$ and $\mathrm{f} 3$ is significantly reduced. The absorption effect of the high-frequency part of the absorber decreased significantly. When h2 is greater than $40 \mathrm{~nm}$, the absorption effect of the absorber between $\mathrm{f} 2$ and $\mathrm{f} 3$ begins to improve again. In summary, when $\mathrm{h} 2$ is adjusted to an appropriate thickness, a wide spectrum of absorption can be formed between $\mathrm{f} 2$ and $\mathrm{f} 3$. When the thickness of $\mathrm{ZnS}$ film h2 is set at about $40 \mathrm{~nm}$, the absorption intensity of absorption peaks at $\mathrm{f} 2$ and $\mathrm{f} 3$ has no obvious change. By observing Figure $6 \mathrm{~b}$, we can see that the absorption map of the absorber is red-shifted after the change of the film thickness of the absorbing Au layer h3. With the augment of Au layer thickness, the absorption rate of the absorber at f1 increases from $90.0 \%$ to $99.7 \%$. This phenomenon indicates that resonant light becomes stronger and stronger in the cavity [62,63]. However, the absorption efficiency between $\mathrm{f} 2$ and $\mathrm{f} 3$ increased significantly, but the absorption efficiency of the highfrequency part after $\mathrm{f} 3$ decreased gradually. This is because the resonance enhancement at $\mathrm{f} 2$ and $\mathrm{f} 3$ results in the red-shifted absorption peak at $\mathrm{f} 3$ from $738 \mathrm{THz}$ to $702 \mathrm{THz}$. Obtaining the results of changing the structural parameters in Figure $6 a, b$, we found that the size of the absorber structure has a great effect on the absorber's performance. Therefore, the selection of appropriate absorber layer thickness h3 and dielectric layer thickness h2 is crucial to whether the absorber can achieve perfect absorption of solar radiation.

It is well known that visible light does not necessarily incident vertically in practical applications. Insensitive to both polarization and angle of incidence, it is an ideal absorber in the minds of researchers. We varied the pitch angle and polarization of the incident light in order to investigate whether the angle of incidence and polarization had an effect on the absorption spectrum of the absorber. We investigated the effect of different polarized light and incident angles on the absorption spectra. The absorption spectrum of the absorber does not change significantly when the incident magnetic field changes to the incident electric field. The absorption spectrum when the incident field is a magnetic field is shown in Figure 7a. Therefore, the absorber is insensitive to TE and TM light. This conclusion is primarily caused by the symmetrical arrangement of the square ring cross structure in the periodic array. The absorption of the absorber at $0-80^{\circ}$ incidence is shown in Figure $7 \mathrm{~b}$. 
When the back oblique incidence angle is $40^{\circ}$ and $60^{\circ}$, the absorption of the absorber begins to decrease in part of the frequency range. The incident light from different angles has an effect on the absorption performance of the absorber. The results suggest that the effect is limited. The calculation results show that the wideband absorber has strong angle sensitivity. The absorptance of the absorber decreases as the angle of incidence increases. This is because as the angle of incidence increases, the component of the incident magnetic field in the $x$-axis direction decreases. The decreasing $\times$ component causes the magnetic flux density between the surface metal blocks to become smaller and smaller. Less and less energy is being absorbed into the absorber. As a result, there will be less and less electromagnetic absorption [64,65]. Despite the increase in the angle of incidence to $60^{\circ}$, the absorber still has a high absorption rate. The absorber can still meet the requirements of many practical applications.
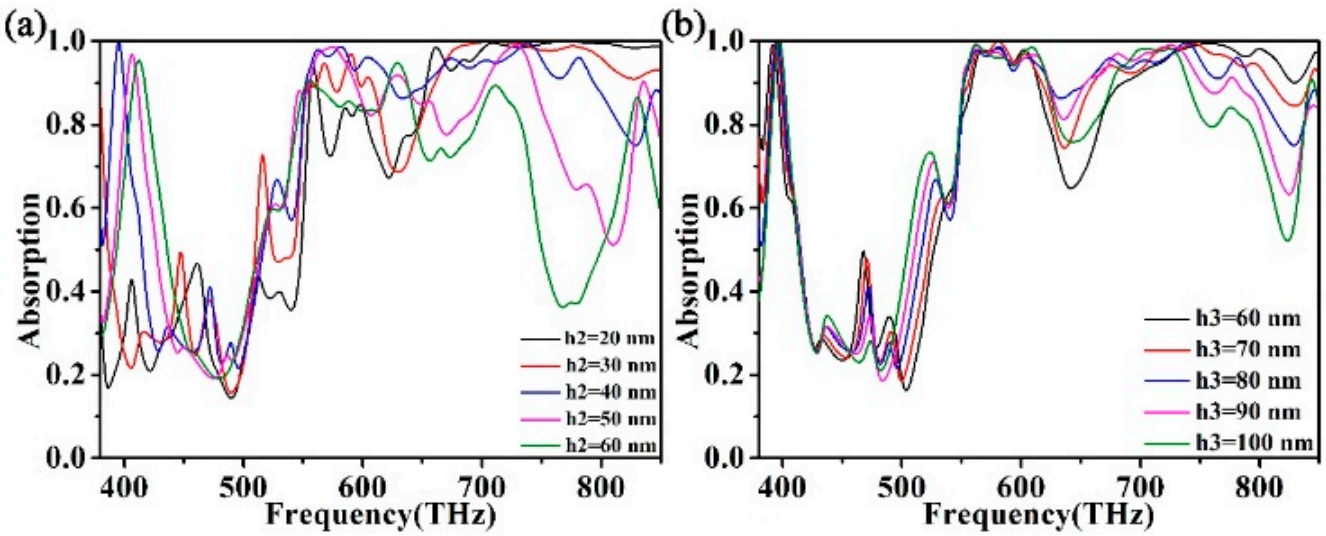

Figure 6. (a) The effect of dielectric layer thickness $\mathrm{H} 2$ on the absorption spectrum. (b) The effect of surface absorption layer thickness $\mathrm{H} 3$ on the absorption spectrum.
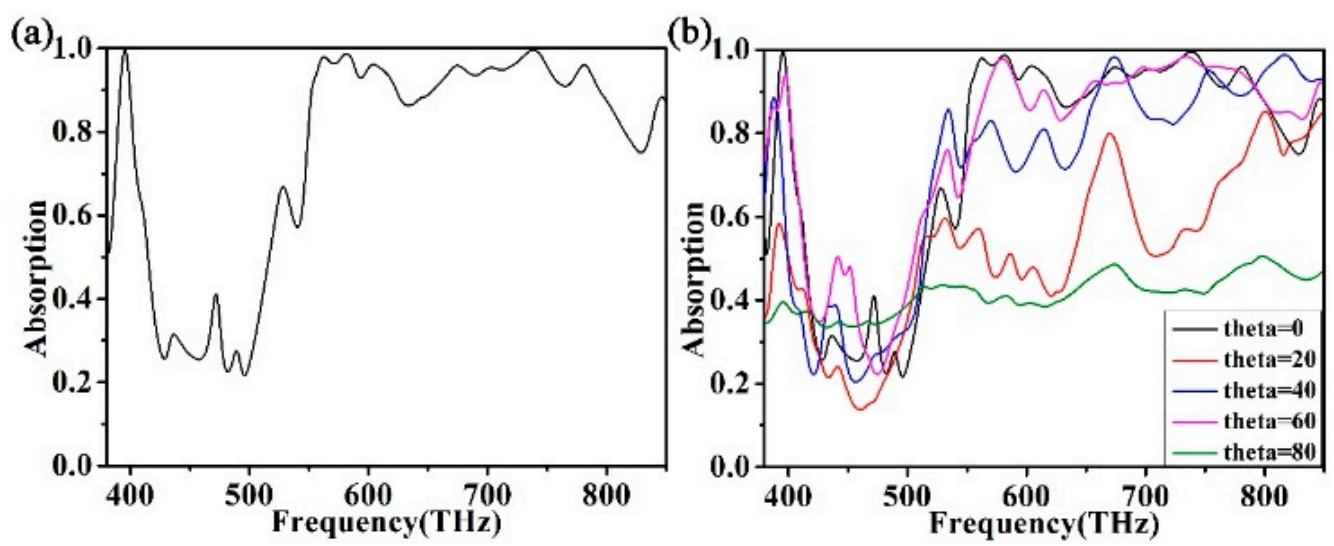

Figure 7. (a) The absorption curve under TM polarization (transverse magnetic, the electric field is parallel to the $x$ direction). (b) The absorption spectrum of the absorber at different angles of incidence.

Finally, we want to understand how each part of the absorber affects the performance of the absorber, and we divided the proposed absorber into two parts for research. We only kept the top square ring structure of the absorber. The absorption spectrum and the top structure are shown in Figure 8a. We can find that there are two better absorption peaks, $\mathrm{f} 4=612 \mathrm{THz}$ and $\mathrm{f} 5=712 \mathrm{THz}$, and their absorptions are $99.1 \%$ and $99.5 \%$, respectively. This result confirms that the wide spectrum absorption caused by the excited surface plasmons is mainly provided by the square ring structure. Figure 9a shows the absorption spectrum of the absorber with only a cross structure. We can find that there are two better absorption peaks, $\mathrm{f} 6=390 \mathrm{THz}$ and $\mathrm{f} 7=566 \mathrm{THz}$, and their absorptions are $99.7 \%$ 
and $99.0 \%$, respectively. The results confirm that the ideal single absorption peak in the low-frequency part is mainly provided by the cross structure when the two structures become the metamaterial absorber proposed in this paper. Due to the superposition of the absorption properties of $\mathrm{f} 4$ and $\mathrm{f} 7$, we finally obtain the absorption efficiency of the absorber at $\mathrm{f} 2$. The ideal absorption peak of the absorber at $\mathrm{f} 6$ is also transferred to $\mathrm{f} 1$ due to the superposition of absorption properties. The ideal absorption peak of the absorber at $\mathrm{f} 5$ is also transferred to $\mathrm{f} 3$. This conclusion is shown in Figure 10. After the cross and square ring are superimposed, the absorption pattern changes from four absorption peaks to three absorption peaks. Due to the interaction of these two structures, we obtained a metamaterial absorber with an ideal absorption peak and a wide spectrum of visible light bands. The design of axisymmetric structures insensitive to polarization is a method to significantly enhance surface plasmon resonance. The final effect of surface plasmon resonance, therefore, rests with the mode structure of the absorbing layer at the top of the metamaterial. By reason of the foregoing, the absorber designed in this paper has a better effect than other absorbers that absorb visible light radiation.
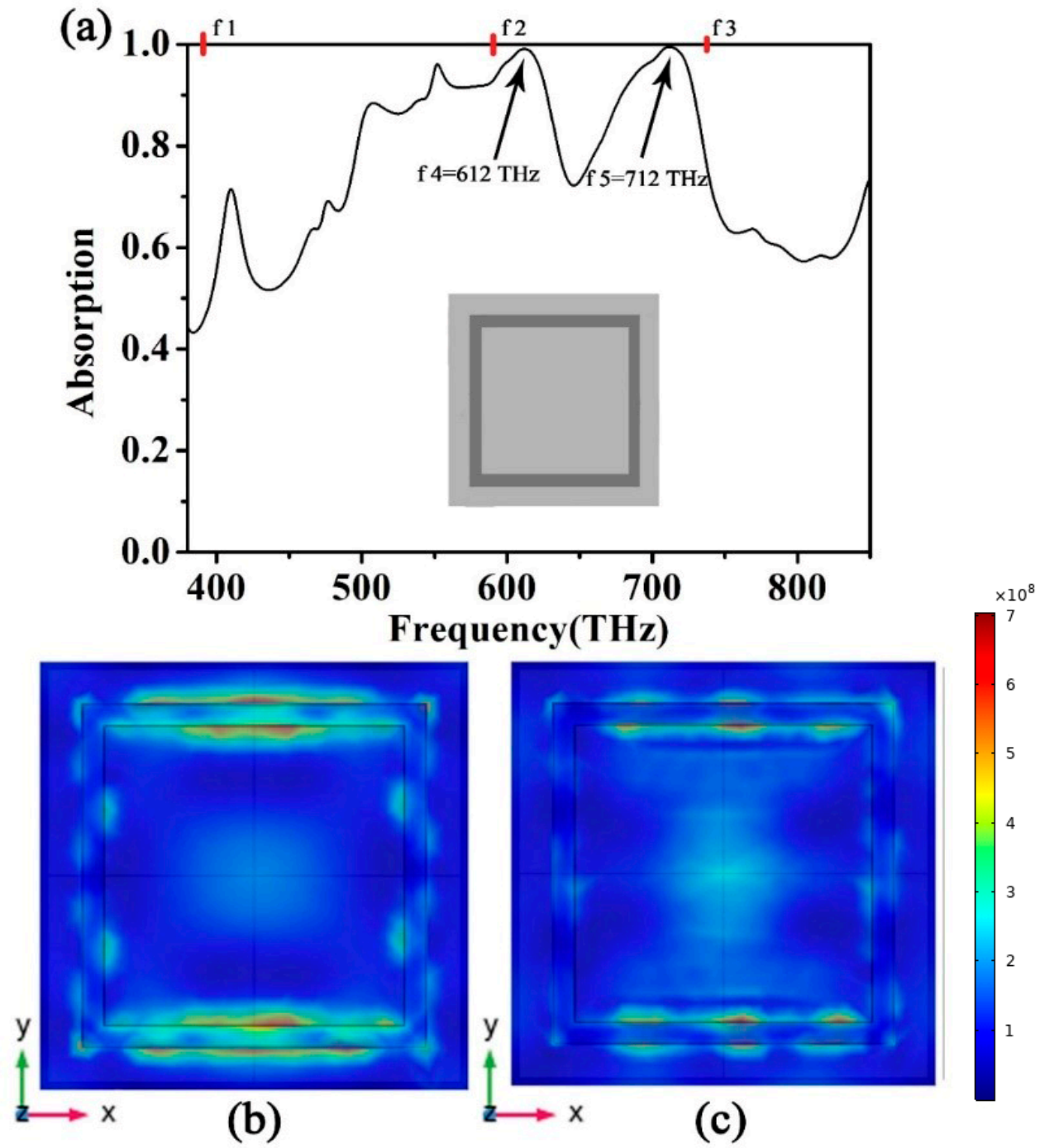

Figure 8. (a) Absorption spectrum of the absorber in the presence of a magnetic field with only a square ring structure. (b) The electric field diagram of the absorber at $\mathrm{f} 4$. (c) The electric field diagram of the absorber at $\mathrm{f} 5$. 

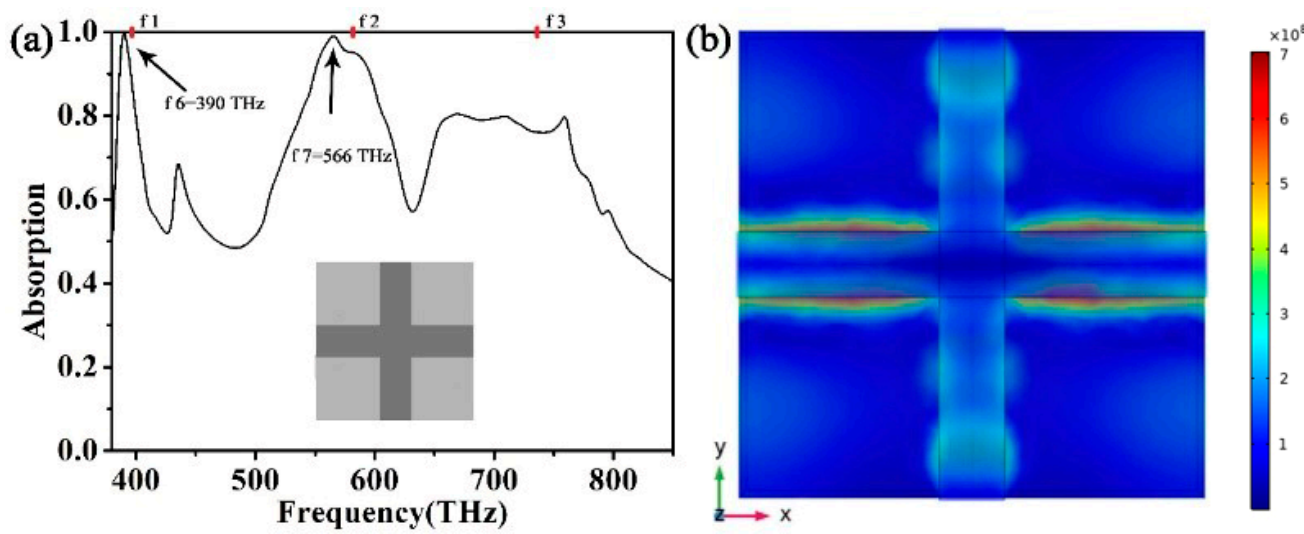

Figure 9. (a) Absorption spectrum of the absorber in the presence of a magnetic field with only the cross structure. (b) The electric field diagram of the absorber at $\mathrm{f} 6$.

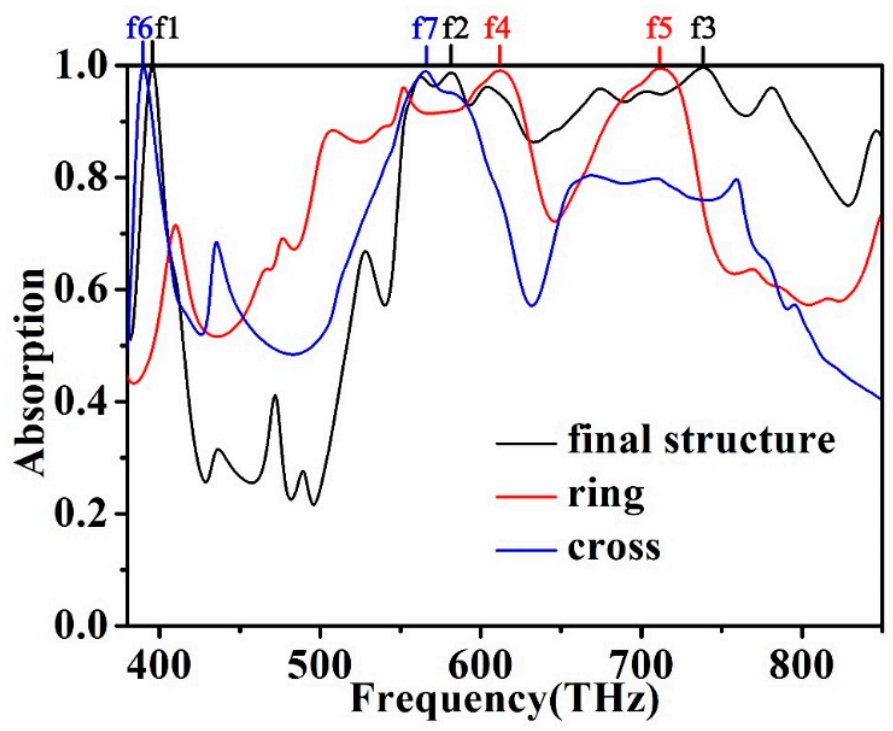

Figure 10. The absorption of the ring, the cross, and the final structure.

\section{Conclusions}

In this paper, a wideband absorber with a stacked membrane structure is designed. Each array element of the absorber is a sandwich structure consisting of a top absorber layer with a square ring cross pattern, a dielectric layer made of $\mathrm{ZnS}$, and a bottom film made of $\mathrm{Au}$. The absorber has an absorbance of more than $90 \%$ in the visible wavelength range of $240 \mathrm{THz}$, with an average absorbance of $94 \%$. There are two maximum absorption peaks in the wide spectrum, $\mathrm{f} 2$ and $\mathrm{f} 3$, with absorption rates of $98.71 \%$ and $99.61 \%$, respectively. There is a perfectly absorbed unimodal $\mathrm{f} 1$ in the low-frequency section, with a maximum absorption rate of $99.7 \%$. Wideband absorption is primarily caused by surface plasmon resonance and gap surface plasmon mode. On this basis, the effects of different structural parameters on the absorption characteristics of the absorber are studied in detail. The ultra-wideband absorption of the perfect absorber proposed in this paper is polarizationindependent. This characteristic allows the absorber to have a good performance of electromagnetic wave absorption under electromagnetic conditions. The material we used has a high thermal stability, which indicates that the absorber has a potential application prospect in high-intensity irradiation and high temperatures. The broadband absorber proposed in this paper has a broad application prospect in solar photovoltaic power generation, stealth, thermal electronic equipment, and other fields. 
Author Contributions: F.X.: conceptualization, formal analysis, investigation, data curation, writingoriginal draft, and writing-review and editing. L.L.: conceptualization, formal analysis, investigation, data curation, and funding acquisition. J.F.: conceptualization, formal analysis, investigation, data curation, writing — original draft, and writing—review and editing. M.H.: conceptualization, formal analysis, and revision. F.W.: conceptualization, formal analysis, and revision. J.S.: conceptualization, formal analysis, and revision. S.L.: formal analysis and funding acquisition. M.P.: conceptualization, formal analysis, and revision. All authors have read and agreed to the published version of the manuscript.

Funding: This research received no external funding.

Acknowledgments: This work was supported by the National Natural Science Foundation of China (21676222, U175252), the Natural Science Foundation of Fujian Province (2019I0017, 2019J01732, JT180365, JAT200552), the Major Program of Natural Science Foundation of Fujian Province for College Young Scholars (No. JZ160456), the Quanzhou high-level Talents Innovation and Entrepreneurship Project (2020C044R, 2020C004R), and the Quanzhou Science and Technology Project (2018C128R).

Conflicts of Interest: The authors declare no conflict of interest.

\section{References}

1. Li, J.; Chen, X.; Yi, Z.; Yang, H.; Tang, Y.; Yi, Y.; Yao, W.; Wang, J.; Yi, Y. Broadband solar energy absorber based on monolayer molybdenum disulfide using tungsten elliptical arrays. Mater. Today Energy 2020, 16, 100390. [CrossRef]

2. Jiang, L.Y.; Yi, Y.T.; Yi, Z.; Yang, H.; Li, Z.Y.; Su, J.; Zhou, Z.G.; Chen, X.F.; Yi, Y.G. A four-band perfect absorber based on high quality factor and high figure of merit of monolayer molybdenum disulfide. Acta Phys. Sin. 2021, 70, 128101. [CrossRef]

3. Jiang, L.; Yuan, C.; Li, Z.; Su, J.; Yi, Z.; Yao, W.; Wu, P.; Liu, Z.; Cheng, S.; Pan, M. Multi-band and high-sensitivity perfect absorber based on monolayer grapheme metamaterial. Diam. Relat. Mater. 2021, 111, 108227. [CrossRef]

4. Li, Z.; Yi, Y.; Xu, D.; Yang, H.; Yi, Z.; Chen, X.; Yi, Y.; Zhang, J.; Wu, P. A multi-band and polarization-independent perfect absorber based on Dirac semimetals circles and semi-ellipses array. Chin. Phys. B 2021. [CrossRef]

5. Yi, Z.; Li, J.K.; Lin, J.C.; Qin, F.; Chen, X.F.; Yao, W.T.; Liu, Z.M.; Cheng, S.B.; Wu, P.H.; Li, H.L. Broadband polarization-insensitive and wide-angle solar energy absorber based on tungsten ring-disc array. Nanoscale 2020, 12, 23077-23083. [CrossRef] [PubMed]

6. Cai, R.; Rao, W.; Zhang, Z.H.; Long, F.; Yin, Y.L. An imprinted electrochemical sensor for bisphenol A determination based on electrodeposition of a graphene and Ag nanoparticle modified carbon electrode. Anal. Methods 2014, 6, 1590-1597. [CrossRef]

7. Deng, Y.; Cao, G.; Wu, Y.; Zhou, X.; Liao, W. Theoretical Description of Dynamic Transmission Characteristics in MDM Waveguide Aperture-Side-Coupled with Ring Cavity. Plasmonics 2015, 10, 1537-1543. [CrossRef]

8. Liu, Y.H.; Bo, M.L.; Yang, X.X.; Zhang, P.P.; Sun, C.Q.; Huang, Y.L. Size modulation electronic and optical properties of phosphorene nanoribbons: DFT-BOLS approximation. Phys. Chem. Chem. Phys. 2017, 19, 5304-5309. [CrossRef]

9. Cai, L.; Zhang, Z.H.; Xiao, H.M.; Chen, S.; Fu, J.L. An eco-friendly imprinted polymer based on graphene quantum dots for fluorescent detection of p-nitroaniline. RSC Adv. 2019, 9, 41383-41391. [CrossRef]

10. Cao, G.; Li, H.; Deng, Y.; Zhan, S.; He, Z.; Li, B. Systematic Theoretical Analysis of Selective-Mode Plasmonic Filter Based on Aperture-Side-Coupled Slot Cavity. Plasmonics 2014, 9, 1163-1169. [CrossRef]

11. Yu, P.; Yang, H.; Chen, X.; Yi, Z.; Yao, W.; Chen, J.; Yi, Y.; Wu, P. Ultra-wideband solar absorber based on refractory titanium metal. Renew. Energy 2020, 158, 227-235. [CrossRef]

12. Lin, K.-T.; Chen, H.; Lai, Y.-S.; Yu, C.-C.; Lee, Y.-C.; Su, P.-Y.; Yen, Y.-T.; Chen, B.-Y. Loading effect-induced broadband perfect absorber based on single-layer structured metal film. Nano Energy 2017, 37, 61-73. [CrossRef]

13. Li, J.; Chen, Z.; Yang, H.; Yi, Z.; Chen, X.; Yao, W.; Duan, T.; Wu, P.; Li, G.; Yi, Y. Tunable broadband solar energy absorber based on monolayer transition metal dichalcogenides materials using Au nanocubes. Nanomaterials 2020, 10, 257. [CrossRef] [PubMed]

14. Chen, H.J.; Zhang, Z.H.; Cai, R.; Kong, X.Q.; Chen, X.; Liu, Y.N.; Yao, S.Z. Molecularly imprinted electrochemical sensor based on a reduced graphene modified carbon electrode for tetrabromobisphenol A detection. Analyst 2013, 138, 2769-2776. [CrossRef] [PubMed]

15. Tang, N.M.; Li, Y.J.; Chen, F.T.; Han, Z.Y. In situ fabrication of a direct Z-scheme photocatalyst by immobilizing CdS quantum dots in the channels of graphene-hybridized and supported mesoporous titanium nanocrystals for high photocatalytic performance under visible light. RSC Adv. 2018, 8, 42233-42245. [CrossRef]

16. Wang, Z.L.; Zhang, Z.M.; Quan, X.J.; Cheng, P. A perfect absorber design using a natural hyperbolic material for harvesting solar energy. Sol. Energy 2018, 159, 329-336. [CrossRef]

17. Cui, Y.; Xu, J.; Fung, K.H.; Jin, Y.; Kumar, A.; He, S.; Fang, N. A thin film broadband absorber based on multi-sized nanoantennas. Appl. Phys. Lett. 2011, 99, 253101. [CrossRef]

18. Ye, L.F.; Chen, X.; Zhuo, J.L.; Han, F.; Liu, Q.H. Actively tunable broadband terahertz absorption using periodically squarepatterned graphene. Appl. Phys. Express 2018, 11, 102201. [CrossRef]

19. Zhang, Y.; Yi, Z.; Wang, X.; Chu, P.; Yao, W.; Zhou, Z.; Cheng, S.; Liu, Z.; Wu, P.; Pan, M.; et al. Dual band visible metamaterial absorbers based on four identical ring patches. Phys. E Low Dimens. Syst. Nanostruct. 2021, 127, 114526. [CrossRef] 
20. Wang, Y.; Yi, Y.; Xu, D.; Yi, Z.; Li, Z.; Chen, X.; Jile, H.; Zhang, J.; Zeng, L.; Li, G. Terahertz tunable three band narrowband perfect absorber based on Dirac semimetal. Phys. E Low Dimens. Syst. Nanostruct. 2021, 131, 114750. [CrossRef]

21. Chen, Z.; Chen, H.; Jile, H.; Xu, D.; Yi, Z.; Lei, Y.; Chen, X.; Zhou, Z.; Cai, S.; Li, G. Multi-band multi-tunable perfect plasmon absorber based on L-shaped and double-elliptical graphene stacks. Diam. Relat. Mater. 2021, 115, 108374. [CrossRef]

22. Chen, Z.; Chen, H.; Yin, J.; Zhang, R.; Jile, H.; Xu, D.; Yi, Z.; Zhou, Z.; Cai, S.; Yan, P. Multi-band, Tunable, High Figure of Merit, High Sensitivity Single-layer Patterned Graphene-Perfect Absorber Based on Surface Plasmon Resonance. Diam. Relat. Mater. 2021, 116, 108393. [CrossRef]

23. Deng, Y.; Cao, G.T.; Yang, H.; Zhou, X.Q.; Wu, Y.W. Dynamic Control of Double Plasmon-Induced Transparencies in ApertureCoupled Waveguide-Cavity System. Plasmonics 2018, 13, 345-352. [CrossRef]

24. Lv, P.P.; Xie, D.D.; Zhang, Z.H. Magnetic carbon dots based molecularly imprinted polymers for fluorescent detection of bovine hemoglobin. Talanta 2018, 188, 145-151. [CrossRef] [PubMed]

25. Long, F.; Zhang, Z.H.; Wang, J.; Yan, L.; Lu, P.P.; Yang, Z.X. Magnetic Graphene Modified Imprinted Electrochemical Sensor for Detection of 4-Octylphenol. Chin. J. Anal. Chem. 2016, 44, 908-914. [CrossRef]

26. Zhang, Z.H.; Cai, R.; Long, F.; Wang, J. Development and application of tetrabromobisphenol A imprinted electrochemical sensor based on graphene/carbon nanotubes three-dimensional nanocomposites modified carbon electrode. Talanta 2015, 134, 435-442. [CrossRef]

27. Cheng, T.; Gao, W.; Gao, H.; Wang, S.; Yi, Z.; Wang, X.; Yang, H. Piezocatalytic degradation of methylene blue, tetrabromobisphenol $\mathrm{A}$ and tetracycline hydrochloride using $\mathrm{Bi}_{4} \mathrm{Ti}_{3} \mathrm{O}_{12}$ with different morphologies. Mater. Res. Bull. 2021, 141, 111350. [CrossRef]

28. Gao, H.; Wang, Y.; Gao, Q.; Pan, X.; Wang, S.; Yang, H.; Chen, C.; Wang, Y.; Fang, L.; Yi, Z. Phase evolution and photoluminescence behavior of MMoO4 (M = Mg, Ca, Sr) phosphors. Optik 2021, 241, 167040. [CrossRef]

29. Su, J.; Yang, H.; Xu, Y.; Tang, Y.; Yi, Z.; Zheng, F.; Zhao, F.; Liu, L.; Wu, P.; Li, H. Based on Ultrathin PEDOT:PSS/c-Ge Solar Cells Design and Their Photoelectric Performance. Coatings 2021, 11, 748. [CrossRef]

30. Zhao, F.; Chen, X.F.; Yi, Z.; Qin, F.; Tang, Y.J.; Yao, W.T.; Zhou, Z.G.; Yi, Y.G. Study on the solar energy absorption of hybrid solar cells with trapezoid-pyramidal structure based PEDOT:PSS/c-Ge. Sol. Energy 2020, 204, 635-643. [CrossRef]

31. Qin, F.; Chen, X.F.; Yi, Z.; Yao, W.T.; Yang, H.; Tang, Y.J.; Yi, Y.; Li, H.L.; Yi, Y.G. Ultra-broadband and wide-angle perfect solar absorber based on TiN nanodisk and Ti thin film structure. Sol. Energy Mater. Sol. Cells 2020, 211, 110535. [CrossRef]

32. Luo, M.H.; Shen, S.; Zhou, L.; Wu, S.L.; Zhou, Y.; Chen, L. Broadband, wide-angle, and polarization-independent metamaterial absorber for the visible regime. Opt. Express 2017, 25, 16715-16724. [CrossRef]

33. Cao, T.; Wei, C.W.; Simpson, R.E.; Zhang, L.; Martin, J.C. Broadband polarization-independent perfect absorber using a phasechange metamaterial at visible frequencies. Sci. Rep. 2014, 4, 3955. [CrossRef]

34. Takatori, K.; Okamoto, T.; Ishibashi, K. Surface-plasmon-induced ultra-broadband light absorber operating in the visible to infrared range. Opt. Express 2018, 26, 1342-1350. [CrossRef]

35. Zhang, B.; Qi, Y.; Zhang, T.; Zhang, Y.; Liu, W.; Wang, L.; Ding, J.; Wang, X.; Yi, Z. Tunable multi-band terahertz absorber based on composite graphene structures with square ring and Jerusalem cross. Results Phys. 2021, 25, 104233. [CrossRef]

36. Kocer, H.; Butun, S.; Li, Z.Y.; Aydin, K. Reduced near-infrared absorption using ultra-thin lossy metals in fabry-perot cavities. Sci. Rep. 2015, 5, 8157. [CrossRef]

37. Wang, Y.; Cui, W.; Ma, H.; Xu, H.; Yi, Z.; Cao, X.; Ren, X.; He, Z. Outstanding slow-light effect for graphene metasurface in terahertz. Results Phys. 2021, 23, 104002. [CrossRef]

38. Li, J.H.; Jiang, J.B.; Xu, Z.F.; Liu, M.Q.; Tang, S.P.; Yang, C.M.; Qian, D. Facile synthesis of Ag@Cu ${ }_{2} \mathrm{O}$ heterogeneous nanocrystals decorated N-doped reduced graphene oxide with enhanced electrocatalytic activity for ultrasensitive detection of $\mathrm{H}_{2} \mathrm{O}_{2}$. Sens. Actuators B Chem. 2018, 260, 529-540. [CrossRef]

39. Guler, U.; Boltasseva, A.; Shalaev, V. Refractory plasmonics. Science 2014, 344, 263-264. [CrossRef]

40. Liu, Z.Q.; Liu, G.Q.; Huang, Z.P.; Liu, X.S.; Fu, G.L. Ultra-broadband perfect solar absorber by an ultra-thin refractory titanium nitride meta-surface. Sol. Energy Mater. Sol. Cells 2018, 179, 346-352. [CrossRef]

41. Li, J.H.; Jiang, J.B.; Zhao, D.; Xu, Z.F.; Liu, M.Q.; Liu, X.; Tong, H.X.; Qian, D. Novel hierarchical sea urchin-like Prussian blue@palladium core-shell heterostructures supported on nitrogen-doped reduced graphene oxide: Facile synthesis and excellent guanine sensing performance. Electrochim. Acta 2020, 330, 135196. [CrossRef]

42. Zhou, F.Q.; Qin, F.; Yi, Z.; Yao, W.T.; Liu, Z.M.; Wu, X.W.; Wu, P.H. Ultra-wideband and wide-angle perfect solar energy absorber based on Ti nanorings surface plasmon resonance. Phys. Chem. Chem. Phys. 2021. [CrossRef]

43. Cheng, T.T.; Gao, H.J.; Sun, X.F.; Xian, T.; Wang, S.F.; Yi, Z.; Liu, G.R.; Wang, X.X.; Yang, H. An excellent Z-scheme Ag2MoO4/Bi4Ti3O12 heterojunction photocatalyst: Construction strategy and application in environmental purification. Adv. Powder Technol. 2021, 32, 951-962. [CrossRef]

44. Wang, Q.; Renema, J.J.; Engel, A. Design of $\mathrm{NbN}$ superconducting nanowire single-photon detectors with enhanced infrared detection efficiency. Phys. Rev. Appl. 2017, 8, 034004. [CrossRef]

45. Zhang, X.; Liu, Z.; Zhang, Z.; Qin, Y.; Zhuo, S.; Luo, X.; Zhou, F.; Yi, Z.; Wang, J.; Wang, Y. Triple plasmon-induced transparency in graphene and metal metamaterials and its anomalous property. J. Phys. D Appl. Phys. 2021, 54, 284001. [CrossRef]

46. Cheng, T.; Sun, X.; Xian, T.; Yi, Z.; Li, R.; Wang, X.; Yang, H. Tert-butylamine/oleic acid-assisted morphology tailoring of hierarchical $\mathrm{Bi}_{4} \mathrm{Ti}_{3} \mathrm{O}_{12}$ architectures and their application for photodegradation of simulated dye wastewater. Opt. Mater. 2021, 112, 110781. [CrossRef] 
47. Liu, Z.; Zhang, X.; Zhou, F.; Luo, X.; Zhang, Z.; Qin, Y.; Zhuo, S.; Gao, E.; Li, H.; Yi, Z. Triple plasmon-induced transparency and optical switch desensitized to polarized light based on a mono-layer metamaterial. Opt. Express 2021, 29, 13949-13959. [CrossRef]

48. Wang, X.X.; Zhu, J.K.; Xu, Y.Q.; Qi, Y.P.; Zhang, L.P.; Yang, H.; Yi, Z. A novel plasmonic refractive index sensor based on gold/silicon complementary grating structure. Chin. Phys. B 2021, 30, 024207. [CrossRef]

49. Qi, Y.; Zhang, B.; Ding, J.; Zhang, T.; Wang, X.; Yi, Z. Efficient Manipulation of Terahertz waves by multi-bit Coding Metasurfaces and its further application. Chin. Phys. B 2021, 30, 024211. [CrossRef]

50. Lin, X.; Li, Y.J.; Chen, F.T.; Xu, P.; Li, M. Facile synthesis of mesoporous titanium dioxide doped by Ag-coated graphene with enhanced visible-light photocatalytic performance for methylene blue degradation. RSC Adv. 2017, 7, 25314-25324. [CrossRef]

51. Cheng, Z.H.; Liao, J.; He, B.Z.; Zhang, F.; Zhang, F.A.; Huang, X.H.; Zhou, L. One-Step Fabrication of Graphene Oxide Enhanced Magnetic Composite Gel for Highly Efficient Dye Adsorption and Catalysis. ACS Sustain. Chem. Eng. 2015, 3, 1677-1685. [CrossRef]

52. He, Z.; Li, L.; Cui, W.; Wang, Y.; Xue, W.; Xu, H.; Yi, Z.; Li, C.; Li, Z. Unidirectional reflectionless propagation of near-infrared light in resonator-assisted non-parity-time symmetric waveguides. New J. Phys. 2021, 23, 053015. [CrossRef]

53. Li, J.; Wang, S.; Sun, G.; Gao, H.; Yu, X.; Tang, S.; Zhao, X.; Yi, Z.; Wang, Y.; Wei, Y. Facile preparation of MgAl2O4/CeO2/Mn3O4 heterojunction photocatalyst and enhanced photocatalytic activity. Mater. Today Chem. 2021, 19, 100390. [CrossRef]

54. Chen, X.F.; Wu, W.H.; Zhang, W.X.; Wang, Z.Y.; Fu, Z.J.; Zhou, L.; Yi, Z.; Li, G.F.; Zeng, L.C. Blue and green double band luminescent carbon quantum dots: Synthesis, origin of photoluminescence, and application in white light-emitting devices. Appl. Phys. Lett. 2021, 118, 153102. [CrossRef]

55. Wu, P.H.; Zhang, C.F.; Tang, Y.J.; Liu, B.; Lv, L. A Perfect Absorber Based on Similar Fabry-Perot Four-Band in the Visible Range. Nanomaterials 2020, 10, 488. [CrossRef] [PubMed]

56. Zhang, Y.; Lv, J.; Que, L.C.; Mi, G.Y.; Zhou, Y.; Jiang, Y.D. A visible-infrared double band photodetector absorber. Results Phys. 2020, 18, 103283. [CrossRef]

57. Huang, H.L.; Xia, H.; Guo, Z.B.; Xie, D.; Li, H.J. Design of Broadband Metamaterial Absorbers for Permittivity Sensitivity and Solar Cell Application. Chin. Phys. Lett. 2017, 34, 117801. [CrossRef]

58. Shobhit, K.P.; Shreyas, C.; Juveriya, P.; Mayurkumar, L. Broadband metasurface solar absorber in the visible and near-infrared region. Mater. Res. Express 2019, 6, 086213. [CrossRef]

59. Cong, J.W.; Zhou, Z.Q.; Yun, B.F.; Lv, L.; Yao, H.B.; Fu, Y.H. Broadband visible-light absorber via hybridization of propagating surface plasmon. Opt. Lett. 2016, 41, 1965-1968. [CrossRef]

60. Li, Z.; Yi, Z.; Liu, T.; Liu, L.; Chen, X.; Zheng, F.; Zhang, J.; Li, H.; Wu, P.; Yan, P. Three-band perfect absorber with high refractive index sensing based on active tunable Dirac semimetal. Phys. Chem. Chem. Phys. 2021. [CrossRef]

61. Fan, J.; Cheng, Y. Broadband high-effciency cross-polarization conversion and multi-functional wave front manipulation based on chiral structure metasurface for terahertz wave. J. Phys. D Appl. Phys. 2021, 53, 025109. [CrossRef]

62. Yang, X.; Zhang, F.; Hu, Y.J.; Chen, D.Z.; He, Z.Q.; Xiong, L.Z. Gold Nanoparticals Doping Graphene Sheets Nanocomposites Sensitized Screen-printed Carbon Electrode as a Disposable Platform for Voltammetric Determination of Guaiacol in Bamboo Juice. Int. J. Electrochem. Sci. 2014, 9, 5061-5072.

63. Zhang, Z.; Liu, Z.; Zhou, F.; Wang, J.; Wang, Y.; Zhang, X.; Qin, Y.; Zhuo, S.; Luo, X.; Gao, E.; et al. Broadband plasmon-induced transparency modulator in the terahertz band based on multilayer graphene metamaterials. J. Opt. Soc. Am. A 2021, 38, 784-789. [CrossRef] [PubMed]

64. Liu, Q.; Jiang, Y.; Sun, Y.D.; Hu, C.J.; Sun, J.D.; Liu, C.; Lv, J.W.; Zhao, J.; Yi, Z.; Chu, P.K. Surface plasmon resonance sensor based on U-shaped photonic quasi-crystal fiber. Appl. Opt. 2021, 60, 1761-1766. [CrossRef]

65. He, Z.; Li, L.; Ma, H.; Pu, L.; Xu, H.; Yi, Z.; Cao, X.; Cui, W. Graphene-based metasurface sensing applications in terahertz band. Results Phys. 2021, 21, 103795. [CrossRef] 